\title{
VARYING INSTITUTIONAL PROCEDURES FOR DEALING WITH STUDENT ACADEMIC MISCONDUCT: A SHORT COMPARATIVE ANALYSIS
}

\author{
Shiva Das Sivasubramaniam, Zeenath Reza Khan
}

\begin{abstract}
Establishing and maintaining academic integrity has always been a focal point amongst all higher education organisations. A few studies have been designed to compare the efficacy of measures/procedures amongst different institutions. Some other attempts were also made to compare the procedures for academic misconduct investigations amongst different institutions about handling potential plagiarisms and/or academic misconducts. The aim of this workshop based investigation was to show the participants, the importance of pro-activeness and practical awareness to establish institutional procedures for handling potential plagiarism and/or academic dishonesty. We wanted to show the inconsistencies in the approaches of conducting academic investigations relating to plagiarism related misconducts.

We have carried out a simple Google ${ }^{\circledast}$ search and selected publicly available institutional policies and procedures of five different international universities representing different geographical representations. The comparison has highlighted the approaches to investigate plagiarism or academic misconduct are varied amongst these universities. Some institutional policies have established clearly defined processes, others have vague and ambiguous procedures. The study has highlighted the importance of investigating institutional procedures in a comparative manner. In order to provide some recommendation of institutional policies and procedures, we would work closely with the European Network of Academic Integrity (ENAI), and other international stakeholders to expand this study in a larger scale.
\end{abstract}

Key words: Institutional Policies, Disciplinary Procedures, Academic Integrity, Misconduct

\section{Introduction}

Establishing and maintaining academic integrity has always been a focal point amongst all higher education organisations. Different institutions use a variety of measures to deter, detect, and discipline student as well as staff misconducts. As for under/postgraduates, the emphasis is now mainly focus against plagiarism and the use of ghost writing. Since these types of behaviours have become a serious challenge to academia, a holistic approach is necessary. Therefore, many institutions have rightfully established (or improved their own) institutional policies, procedures and proactive strategies. The objective of policies/procedures is to provide clear guidance with institutional expectations. They should ensure a high degree of understanding, cooperation, and good practice amongst the students and staff. On the other hand, institutional proactive strategies, include educational workshops/training, honour codes to deter plagiarism and disciplinary processes to punish the offenses (Kibler, 1993; Cole and McCabe, 1996). 
The institutional policies, in theory, should provide fair, and appropriate responses that are consistent and transparent in detection and/or handling of suspected plagiaristic activities. Since "plagiarism", in practice, comprises of a spectrum of different dishonest behaviours including collusion, ghost writing, unattributed copying, submission of another student's work etc., robust institutional policies are important. In fact, these policies are vital in delivering a clear message to the student (and staff) about institutional perspective on plagiarism. As Cole and Conklin (1996) pointed out "students learn from institutions' responses to academic dishonesty and from institutions' expectations about students". Also, due process policy responses are equally important to deter plagiarism (Academic Integrity Project, 2013). Several authors have studied about the effectiveness of institutional policies, and compared different policies (Martin, 2014; Glendinning, 2014; Foltýnek and Glendinning, 2015; Macdonald and Carroll, 2006; Hua and Sun, 2017; Rodafinos, 2018). In 2013, a large scale EU funded project, impact of policies for plagiarism in higher education across Europe (IPPHAE) have reported the strategies, including policies and procedures employed or implemented by different institutions in 27 EU countries. The study is now being extended to other countries. Apart from IPPHAE, there are only a few studies designed to compare the efficacy of measures/procedures amongst different institutions. In fact, no attempts were made to compare the procedures for academic misconduct enquiries handling a potential plagiarism/academic misconduct amongst different institutions.

Especially the steps, academic involvement, resource use and the robustness of the procedures from the point of "suspected academic misconduct" until it is resolved (either with sanctions or the case acquitted). On the other hand, discussions with fellow academics and students (during academic investigation or otherwise), have indicated their understandings about institutional procedures are somewhat blurred. Students, on one hand, showed less interest in reading these policies. Quotes such as "these are only guidelines, and therefore no need to understand"; or "we are here to study, not to read polices" are commonly voiced by many students. On the other hand, some academics said "the policies are for reference purposes only; they are here to protect the university from law suits". These observations indirectly emphasise the importance of establishing institutional policies and procedures that can be easily understood by the users (i.e. students and academics). Thereby, due processes can be taken forwards in the event of any potential breaches. This workshop attempted to compare the procedures of five different institutions to understand the robustness of these processes.

The aim of this workshop was to show the participants, the importance of proactiveness and practical awareness to establish institutional procedures for handling potential plagiarism and/or academic dishonesty.

\section{Methods}

The investigation was carried out according to research ethics policy and code of practice in University of Derby. Initially a simple Google ${ }^{\circledR}$ search was employed to randomly select publicly available institutional policies of five different international universities. The selection includes universities from America, EU, UK, Australia and Asia to provide 
a geographical representation. The names of the institutions were anonymised (and arbitrarily assigned as A to E), as the aim of this study (and related workshop) is to compare and contrast the due processes of academic misconduct enquiries in different institutions. Dishonouring any institutions and their due processes is beyond the scope of this study. These procedures were summarised in the form of flow charts for easy comparison. Since this is a qualitative study, a narrative comparison (with some discussions) of the procedures amongst these five universities is provided (see below).

\section{Narrative commentary on varying institutional policies}

Interestingly, the comparison of summary flow charts has shown a wide range of due processes. In fact, each institution has its own unique procedures for academic enquiry, involving different members of staff including academics, registry, special officers (such as academic integrity or misconduct officers) etc. These procedures are summarised in figures 1 to 5 below.

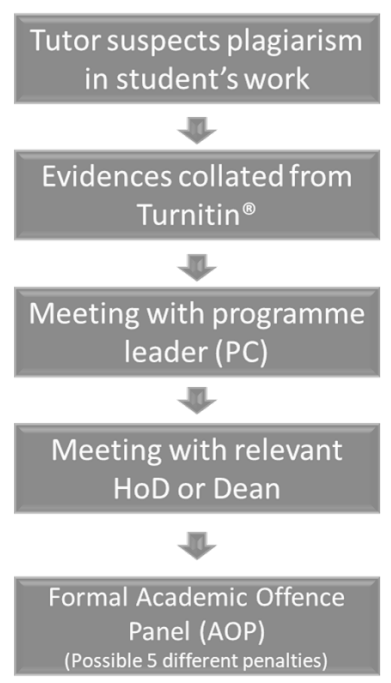

Figure 1. Flow chart summary of academic investigation procedures of university A

Procedures are summarised according to author's interpretation. This particular university uses Turnitin ${ }^{\circledR}$ software for text matching PC = programme coordinator; HoD $=$ Head of the Department

Figure 1 summarises the procedures followed in one of the universities (university A). The procedure starts with tutor/academic suspecting potential plagiarism. Policy states that collecting supporting evidences for the accusations are expected to be carried out by the academic who then pass the "case" to the respective programme coordinator/leader (PC/PL). He/She then inspects the case, conduct an initial meeting with the student(s) to explore the case.

Should the student(s) accept the accusation, PC/PL will decide the course of actions/penalties. Although there is no clarity about the penalties, a general state- 
ment describes depending on the seriousness of the misconduct, PC/PL may impose penalties such as capping the mark allocation, re-work/resubmission or may request the dean (or head of the department - HoD) to decide. The procedure up to this is considered as informal, and therefore no records (or minutes) are created about this incidence. If student fails to attend the meeting with the PC/PL, denies the accusation, or the case seems to be too complicated to be handled by the PC/PL, it is then passed it on to the dean/head of the department, who will carry out the formal investigation involving all parties and decide the fate/penalties. The prescribed penalties are similar to the ones at PC/PL level with the additional options of either failing the student or dismissal (due to seriousness of the misconduct). Finally, in the event of the dean/HoD failing to conclude a decision, the case is passed onto a college based formal academic investigation panel, which investigate and action according to the guidelines given in the policy (possible 5 different levels of sanctions from resubmission (for a capped mark) to expelling from the university. In summary, there are three important levels of investigations namely PC/PL, the dean/HoD and/or formal academic investigation panel. However, for the first two levels, the decision making is depended on a single academic. It was not clear that the academics involved were trained to handle academic offences in accordance with the policies. Moreover, there is no clear guidance on penalties for the first two levels. This would, in practice, result in inconsistencies in the approach, and sanctions applied. Most importantly, penalties are mainly linked to "severity" of the offense but no consideration for academic level.

The procedures for academic investigation in the university B is entirely different (see figure 2). There is a defined "school academic investigation panel" (SAIP) to handle misconducts. The tutors (academics), and the HoDs would prepare, check and determine whether any investigation is needed (or not) but then pass the case to SAIP. Also the accusation is independently verified by two academics before the case is passed to the HoD. All academic misconducts are dealt with one schoolwide panel which meets on regular basis. Maintaining a centralised panel would help maintaining consistency, and record keeping. However, it is not clear how it is represented, whether it consist of several members (whose representation would be on voluntary basis). Also, authors were unable to verify whether these panel members have been specifically trained in accordance with the institutional policy.

The institutional guidelines state a possible 8 different penalties which are linked to the severity of the offence, the number of times it happened (i.e. whether repeat offence), and the level of studies (entry, mid, final and/or Master levels). It looks like the penalties are made in full consideration of the nature of offense in relation with student attitude, academic abilities, and their level of study.

Procedures are summarised according to author's interpretation. Matching. Head of the Department; SAIP = School academic investigation panel

The academic investigation process in university $C$ is unique, in that the misconduct investigation is removed from the subject specific academics and handled by academic integrity officers (or AIOs). These AIO's are specially trained to promote academic integrity, not only taking measures to educate the students to deter plagiarism and other misconducts but also to handle potential plagiarism and other offenses. When a tutor/academic suspects plagiarism, the case is passed to AIO who then schedule 


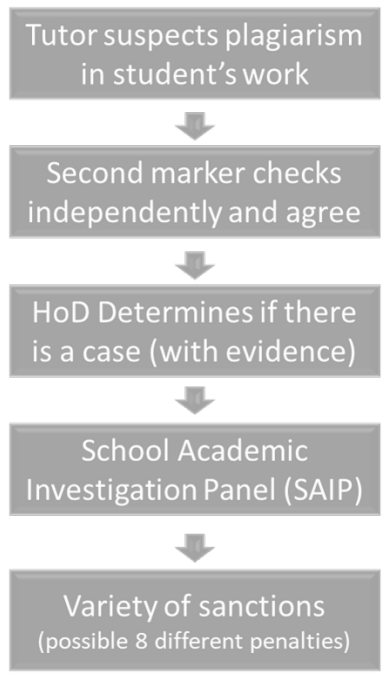

Figure 2. Flow chart summary of academic investigation procedures of university B

an informal meeting with the student(s) to discuss the issue, investigate and collect further evidences. Depending on these, the AIO decides about the penalties (if any). Based on severity, there are four different penalties prescribed, compulsory revision \& resubmission; zero grade for assignment, failure of course, and suspension or expulsion from institution. Yet there is no evidence whether these are linked to the level of study or not. The investigation is centrally documented and therefore available for future references.

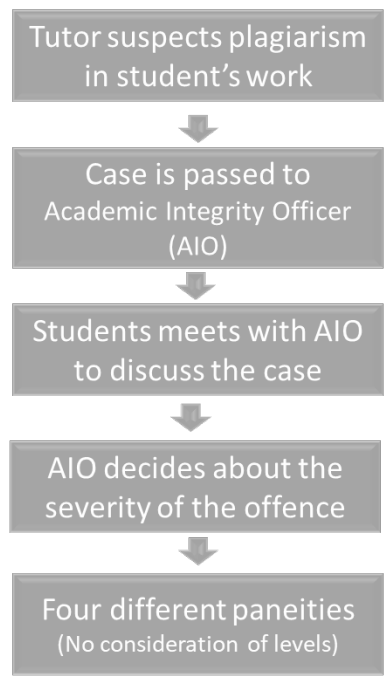

Figure 3. Flow chart summary of academic investigation procedures of university $\mathrm{C}$ 
Procedures are summarised according to author's interpretation. Matching. AIO = Academic integrity officer

The procedures for the university $\mathrm{D}$ is almost identical to university $\mathrm{C}$ but the only difference is the academic conduct officer (ACO) does the initial data/evidence gathering, analyse the case and passed it to an institutional level academic ethics conduct panel (AECP). There are some advantages of having an institutional wide conduct panel. A centralised panel would help to maintain consistency and the records can be kept and revisited by any schools/colleges or departments. This is especially useful to the combined courses where two or more schools/departments are involved. However, it is not clear about the memberships of this panel. Is this the same panel? Are the members undergoing regular training? These questions remain to be answered.

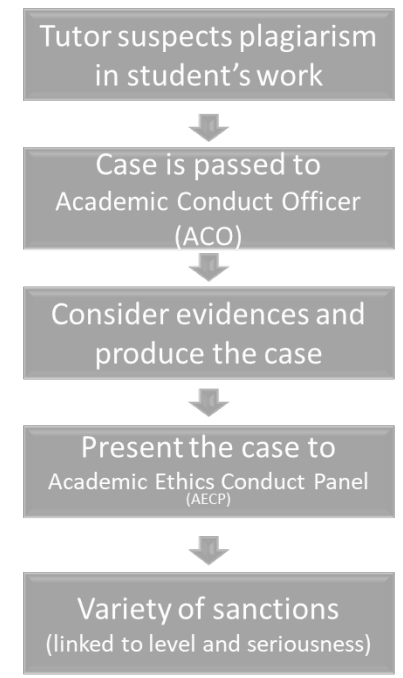

Figure 4. Flow chart summary of academic investigation procedures of university D

Procedures are summarised according to author's interpretation. Matching. ACO = Academic conduct officer; AECP = academic ethics conduct panel

The investigation procedures of university $\mathrm{E}$ is based according to the "severity" of the misconduct (See figure 5). Any misconduct is linked to percentage matches and weighting of the submission. If the percentage copied is less than $10 \%$ of the work, it is handled by the module convener (or leader) who may apply penalty such as $10 \%$-mark reduction. If this is more than $10 \%$ but less than one third of the submitted work, it is handled by the programme leader. Submissions with more than one third plagiarism are handled by the departmental panel.

Procedures are summarised according to author's interpretation. Complex levels handling depending on the "severity" of the misconduct (i.e. up to $10 \%$ match - module convener; more than $10 \%$ match - programme leader; more than $1 / 3$ of component Departmental panel) 


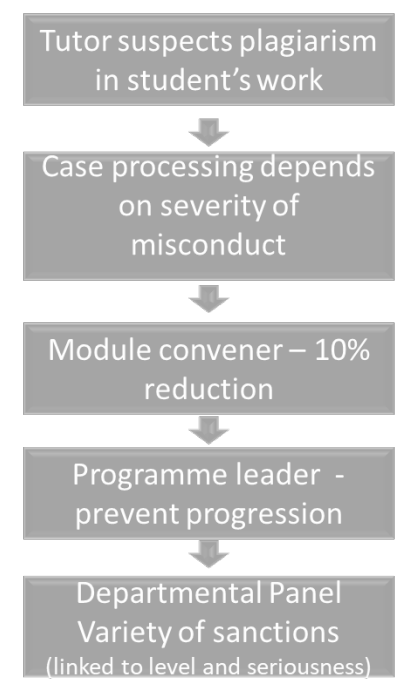

Figure 5. Flow chart summary of academic investigation procedures of university E

In our opinion, the procedure itself is too confusing which lacks vision. Firstly, the process is based on percentage plagiarised. It was not clear how this was measured. Does this mean they are relaying on percentages given by the text matching software such as Turnitin?

Secondly, depending on the "percentage matches" the case would be handled by three different individuals/panels. Despite the fact that there is a centralised documentation, it is not clear whether there be consistency in decision making?

\section{Concluding remarks}

This paper is based on a comparative analysis on the institutional policies and their effectiveness of a cross sectional selection of five universities around the world. By presenting this in a workshop at the 6th international conference on plagiarism across Europe and beyond, authors intended to generate a critical discussion to set up a general institutional guideline for academic investigation procedures. However due to the unexpected global pandemic and the resultant online delivery of this workshop, it was not possible to fulfil the second aim. Therefore, we are presenting this as authors' analysis with comparative comments.

The importance of robust institutional policies has been emphasised by several authors (Benso et al, 2019; Morris, 2018; Foltýnek and Glendinning, 2015). These procedures should be well thought probably involving all stakeholders, including academics, and student bodies (Akin and Johnson 2018). They should be transparent and due considerations should have been taken to protect the innocent victims. However, this initial comparison of these five different procedures does not show these considerations have been taken in majority of universities investigated in this study. This brief analysis 
has highlighted a variety of approaches towards handling academic misconduct, some mainly focussed on plagiarism, others have considered other offenses. We have compared the procedures and produced flow charts based on their policies/procedures. Interestingly, the prescribed panels that handle these offences, in three (out of five) institutions were comprised of academics; and in some cases the academics who were involved in detecting/supporting the claim for plagiarism. It is not clear, how this setting would be fair, or would maintain confidentiality/anonymity. Others use a special panels of members of non-academics or academic support officers, who are specially trained to handle these offenses in accordance to their institutional policies. By this way, these institutions make sure the panel considering the accusation (whether it is plagiarism or not) is not involved in the assessment of work. At least one university used academics from a different discipline to handle these issues. Another institution selected members on ad-hoc or voluntary basis. This might result in inconsistencies in decision making as it was not clear whether these academics are trained to handle these accusation, especially in accordance with the institutional policies.

As for definition of severity of the offences, it was found to be varied amongst these institutions. Some have clearly defined different types of academic misconduct/plagiarism with pre-defined "tariffs". For example, using Carroll \& Seymour's (2006) simple classification, some universities have categorised plagiarism as (a) poor academic practice, (b) academic misbehaviour, and (c) academic misconduct and prescribed appropriate punishments for each of these categories. At least one institutional policy (university D) provided further explanation on defining the "severity" of these offenses. Its policy considered each occurrence of plagiaristic behaviour in two measurable characteristics namely, "intention" - the student's intention to deceive the marker (on a scale of o to 10); and "extent" - the amount of plagiarism (expressed as a percentage of the submission). It further explains, how to combine these two variables under different permutations. By comparing varying levels of "intention" and "extent", the policy tries to link different plagiaristic behaviour with probable penalties. On the other hand, other institutional policies are not explicit on defining different types of plagiaristic behaviours and linking them with tariffs. In contrast another institution (university E), simply linked the "severity" to percentage matches. Most institutions in this study have measures in place to maintain a clear record keeping that would help in investigating repeat offences.

In summary, this initial comparison of policies highlighting due processes in a small sample of five different institutions, has highlighted the approaches to investigate plagiarism or academic misconduct are varied. Some institutional policies have established clearly defined processes, others have vague and ambiguous due procedures. Although the original intention of this workshop was to present, discuss, and try to conclude the important elements within institutional investigation processes by involving the conference participants, we were unable to do so. Therefore, presenting this as a short paper, however the study has highlighted the importance of investigating institutional procedures in a comparative manner to provide some recommendation of institutional policies and procedures. As a part of the European Network of Academic Integrity (ENAI), we would work closely with other partners and international stakeholders to carry out a larger study and report in the future. 


\section{References}

ACAdemic Integrity Project. (2013). Embedding and extending exemplary academic integrity policy and support frameworks across the higher education sector. Office for Learning and Teaching Strategic Commissioned Project 2012-2013. Retrieved from https://lo.unisa.edu.au/course/view.php?id=6751

AкIN, I., \& Johnson, E. (2018). Cultivating Academic Integrity in a Digital Learning Environment. International Journal of Digital Society (IJDS): 91) https://infonomics-society.org/wp-content/uploads/ijds/published-papers/volume-9-2018-2/ Cultivating-Academic-Integrity-in-a-Digital-Learning-Environment.pdf

Benson, L., Rodier, K., Enström, R., \& Bocatto, E. (2019). Developing a university-wide academic integrity E-learning tutorial: a Canadian case. International Journal for Educational Integrity 15, 5. https://doi.org/10.1007/s40979-019-0045-1

Carroll, J., \& Seymour, D. (2006) The effect of a penalty tariff on consistent decision-making in cases of student plagiarism. In: 2nd International Plagiarism Conference, June 19-21, 2006.

Cole, S., \& Conklin, D. L. (1996). Academic integrity policies and procedures: opportunities to teach students about moral leadership and personal ethics, College Student Affairs Journal 15(2), 30-39.

Cole, S., \& McCABE, D. L. (1996). Issues in academic integrity, New Directions for Student Services 73, 67-77. https://doi.org/10.1002/ss.37119967307

FOLTÝNEK, T., \& GLENDINNING, I. (2015). Impact of policies for plagiarism in higher education across Europe: Results of the project. Acta Universitatis Agriculturae et Silviculturae Mendelianae Brunensis 63(1), 207-216. DOI: 10.11118/actaun201563010207

HuA, G., \& Sun, X. (2017). Institutional policies on plagiarism: The case of eight Chinese universities of foreign languages/international studies. System 66, 56-68.

Kibler, W. L. (1993). A Framework for Addressing Academic Dishonesty from a Student Development Perspective. NASPA Journal. 31:1, 8-18 DOI: 10.1080/o0220973.1993.11072332

Morris, E. J. (2018). Academic integrity matters: five considerations for addressing contract cheating. International Journal for Educational Integrity 14, 15. https://doi.org/10.1007/s40979-018-0038- 5

GLENDINNING, I. (2014). Responses to student plagiarism in higher education across Europe. International Journal for Educational Integrity. 10(1), 4-20 ISSN 1833-2595

Macdonald, R., \& CARroll, J. (2006). Plagiarism - a complex issue requiring a holistic institutional approach. Assessment \& Evaluation in Higher Education, 31(2), 233-245.

Martin, B. (2004). Plagiarism: Policy against cheating or policy for learning? Nexus. Newsletter of the Australian Sociological Association, 16(2), 15-21

RodAfinOs, A. (2018). Plagiarism management: Challenges, procedure, and workflow automation. Interdisciplinary Journal of e-Skills and Lifelong Learning, 14, 159-175. DOI:10.28945/4147

\section{Authors}

Shiva Das Sivasubramaniam, University of Derby, Kidleston Road, DE22 1GB Derby, United Kingdom, e-mail: S.Sivasubramaniam@derby.ac.uk

Dr Zeenath Reza Khan, University of Wollongong in Dubai, Knowledge Park, 20183 Dubai, United Arab Emirates, e-mail: zeenath.khan@gmail.com 